\title{
Temperamental traits as predictors of effectiveness of psychotherapy (prolonged exposure) for PTSD in a group of motor vehicle accident survivors
}

\author{
Agnieszka Popiel ${ }^{1 \cdot A, B, C, D, E, F}$, Bogdan Zawadzki $i^{2 \cdot C, D, E, F, G}$ \\ 1: Faculty of Psychology, University of Social Sciences and Humanities, Warsaw, Poland \\ 2: Faculty of Psychology, University of Warsaw, Warsaw, Poland
}

BACKGROUND

The aim of the study was to analyze demographic (age, gender and education), temperamental (briskness and emotional reactivity) and psychopathological (severity of the disorder, comorbid symptoms of personality disorders) predictors of effectiveness of psychotherapy (Prolonged Exposure; PE) of posttraumatic stress disorder (PTSD). It was expected that temperamental traits - briskness (BR) and emotional reactivity (ER) (involved in arousing and change of PTSD symptoms) - would predict the post-treatment diagnosis of PTSD, regardless of severity of PTSD and symptoms of personality disorders.

\section{PARTICIPANTS AND PROCEDURE}

The logistic regression done on findings obtained in the combined sample of 123 motor vehicle accident (MVA) survivors, participating in PE within randomized and non-randomized trials.

\section{RESULTS}

A significant effect of severity of pre-treatment PTSD (lower rate of remission in subjects with more severe PTSD), briskness (higher rate of remission in high BR subjects) and interaction between ER and time after MVA (lower rate of remission in high ER subjects treated in a longer period after MVA) were observed. The effect of personality disorders was not significant due to the remarkable correlations with other predictors.

\section{CONCLUSIONS}

In the discussion the possible mechanisms of the impact of temperamental traits on recovery from PTSD under psychotherapy are suggested, including behavioral plasticity (briskness) and the relationship between subjects' motivation for treatment and the opportunity of successful recovery (determined by comorbid personality disorders), explaining the interactional effect of emotional reactivity.

\section{KEY WORDS}

PTSD; temperament; briskness; emotional reactivity; effectiveness; psychotherapy; prolonged exposure; MVA survivors

CORResPonding AUthor - Agnieszka Popiel, Faculty of Psychology, University of Social Sciences and Humanities,

19/31 Chodakowska Str., 03-815 Warsaw, Poland, e-mail: apopiel@swps.edu.pl

Authors' Contribution - A: Study design - B: Data collection - C: Statistical analysis - D: Data interpretation .

E: Manuscript preparation · F: Literature search · G: Funds collection

TO CITE this ARTICLE - Popiel, A. \& Zawadzki, B. (2013). Temperamental traits as predictors of effectiveness of psychotherapy (prolonged exposure) for PTSD in a group of motor vehicle accident survivors. Current Issues in Personality Psychology, 1, 43-50. 


\section{BACKGROUND}

Evidence-based psychotherapy for PTSD - a group of methods, mainly cognitive-behavioral, under the name "trauma-focused psychotherapy" - proved to be effective in $60-80 \%$ of cases of patients suffering from PTSD (NICE, 2005). Lower efficacy, but still exceeding placebo, has been found for pharmacotherapy, mainly SSRI treatment. Effectiveness of treatment has been differently conceptualized across the studies as significant improvement or remission (not meeting the criteria required for PTSD diagnosis at post-treatment; see: Jacobson \& Truax, 1991, Popiel \& Pragłowska, 2008). Regardless of different mechanisms of action of those effective treatments there remains a stable number of approximately $20-30 \%$ of patients for whom treatments proved to be ineffective, leading to insufficient improvement on continuous measures, or after the treatment patients still met the diagnostic criteria for PTSD. On the other hand, both research data and clinical practice indicate that one unsuccessful treatment does not exclude a good result of another treatment. In order to tailor the best possible treatment for the patient the analysis of predictors of treatment outcome seems essential.

Studies on predictors of psychotherapy outcome focused on: demographic variables (age, sex, education, marital status), clinical/psychopathology (severity of PTSD, comorbid disorders), trauma and peritraumatic emotions (type and time from the trauma, anger, guilt, shame). Except for PTSD symptom severity at the beginning of treatment, which has been systematically found to predict greater symptom severity at the end of therapy (without influencing the degree of improvement; Van Minnen, Arntz \& Keijsers, 2002; see NICE, 2005), other factors were found to have no influence on the outcome, or the results of various studies were contradictory.

The impact of personality disorders on treatment effectiveness belongs to such areas with ambiguous results. Although the general beliefs about more unfavorable treatment outcome in subjects with comorbid personality disorders are widely held by clinicians, the research data are limited. The empirical studies on treatments for anxiety disorders (with PTSD subgroups) found the relationship either weaker than expected or not significant (Tarrier, Sommerfield, Pilgrim \& Faragher, 2000; Weertman, Arntz, Schouten \& Dreessen, 2005), and not significant when prolonged exposure was the treatment in question (Hembree, Cahill \& Foa, 2004).

Normative personality factors have been studied as risk factors for developing PTSD, but available treatment outcome studies have taken into account personality features rarely, or found no impact on treatment outcome (Tarrier et al., 2000; Van Minnen et al., 2002).
It seems, however, that the findings about differentiated biological mechanisms of action of psychotropic medication redirected some researchers' attention to temperamental traits - the most biologically rooted personality traits - as potential predictors of treatment effectiveness. Very few available studies referred mainly to Cloninger's concept linking specific traits to neurotransmitter systems (Cloninger, Svrakic \& Przybeck, 1993). Some findings indicate possibly different mechanisms of action of different psychotherapies, as in the study of Joyce et al. (2007), who found a negative impact of temperamental trait harm avoidance on the result of the interpersonal therapy, but no significant influence on cognitive therapy of depression.

None of the published studies referred specifically to temperamental traits in relation to treatment outcome of the treatments for PTSD. One of the hypothesized mechanisms of temperament interaction with an extreme stressor resulting in psychopathological symptoms of PTSD may be a failure of extinction of fear responses (Lommen et al. 2013; Wessa \& Flor, 2007). Wessa and Flor (2007) found that PTSD patients displayed higher conditioned responses that did not become extinct, while trauma-exposed persons without PTSD showed similar conditionability, but quick extinction of the conditioned response. The authors conclude that their findings support etiological theories of PTSD that favor a Pavlovian conditioning account and suggest that the extinction deficit in PTSD patients observed in this study underlines the need for therapies focusing on the extinction of learned responses, such as behavioral treatment with or without the addition of pharmacological substances that enhance the extinction of a learned response (see also: Lehner, Wisłowska-Stanek, \& Płaźnik, 2009).

Prolonged exposure is a treatment rooted in the behavioral approach so by definition focusing on extinction and the Regulatory Theory of Temperament (RTT) (Strelau, 1998) evolved from Pavlovian theory, so looking for temperamental factors that might be related to a more successful result of the treatment seems natural. According to RTT, emotional reactivity (ER) is defined as an individual tendency to react intensively to emotion-generating stimuli expressed in high emotional sensitivity and low emotional endurance (Strelau \& Zawadzki, 1993). This trait reflects the level of emotional arousability, and it is also related to neuroticism (Strelau \& Zawadzki, 1993) and harm avoidance (Hornowska, 2003). Several studies done on natural (e.g. flood; Strelau \& Zawadzki, 2004) and technological catastrophes (e.g. motor vehicle accidents; Zawadzki \& Popiel, 2012) have shown that emotional reactivity is involved in the process of inducing as well as maintaining/change of PTSD symptoms (low ER subjects are less prone to develop PTSD and demonstrate a greater decrease of symptoms in time due to the natural recovery). Another trait re- 
lated to PTSD is briskness (BR) defined as a tendency to react quickly, to keep a high tempo in performing activities, and to switch easily in response to changes in the surroundings from one behavior (reaction) to another (Strelau \& Zawadzki, 1993). The studies showed that briskness reflecting individual behavioral plasticity predicts the change of the PTSD symptoms in time (Zawadzki \& Popiel, 2012).

The main focus of this paper was on demonstrating the role of two temperamental traits, emotional reactivity and briskness, in remission of PTSD symptoms after psychotherapy. It was expected that high briskness (H1) and low emotional reactivity (H2) would predict recovery regardless of severity of pre-treatment symptoms of PTSD (H3) and symptoms of personality disorders (H4) related to PTSD. No specific expectations were drafted with regard to other variables, such as demographic ones, time since the MVA, and their possible interactions with temperamental traits.

\section{PARTICIPANTS AND PROCEDURE}

\section{PARTICIPANTS}

Two groups of patients participating in PE therapy were taken into account, consisting of 89 (randomized assignment) and 34 subjects (non-randomized assignment). According to our hypotheses, drop-out cases were not taken into account, so the final groups are based on therapy completers. All subjects participated in motor vehicle accidents (MVA) and entered the study at least 1 month (minimal time criterion for the PTSD diagnosis) up to 48 months after the accident. Analyses have shown that the two groups did not differ with regard to any (except age) variable considered in this study (even therapy effectiveness - non-randomized treatment showed a slightly higher, but not statistically significant remission rate: $85 \%$ versus $81 \%$; see Figure 1$)$, so finally two groups were combined into one sample $(N=123)$, and all analyses were performed on data obtained from all subjects. Demographic characteristics of both groups and combined sample are presented in Table 1.

\section{PROCEDURE}

Prolonged exposure (PE) - the cognitive-behavioral treatment protocol for PTSD developed by Foa, Hembree \& Rothbaum (2007) - was applied. The therapy, comprising 8-12 sessions (90 minutes each), was delivered by licensed CBT therapists, under regular supervision. Psychotherapy was a part of a broader project, TRAKT-I, in which three forms of treatment of PTSD were offered to subjects: pharmacotherapy (paroxetine), psychotherapy (PE) and combined ther- apy (PE plus paroxetine). Subjects were randomly assigned to the therapy mode. Those who refused the assigned treatment were referred to alternative places where therapy was available 'out of the project' (mainly community treatment centers). Refusal happened more frequently after assignment to the pharmacotherapy condition. The majority of those patients were contacted later and agreed to participate in another, open study on psychotherapy conducted in our center. Due to this procedure another, non-randomized PE group was formed, whose status reflects the interaction of subjects' preferences and mode of therapy.

Participants were recruited via internet, mail announcements; most were however self- and clinician referrals. After signing the informed consent, participants underwent screening (a set of self-report measures) and pre-treatment clinical diagnosis, assignment to treatment, therapy and independent post-treatment examination (details of the study in Popiel, Zawadzki, Pragłowska \& Teichman, in preparation). The study was approved by institutional ethics committees at the University of Warsaw and the Military Institute of Aviation Medicine in Warsaw and was conducted at the Interdisciplinary Center for Behavioral Genetic Research at UW.

\section{INSTRUMENTS}

Diagnosis of PTSD was done by psychiatrists independent from the therapy staff according to the Structured Clinical Interview for DSM-IV Axis I disorders - module for PTSD (SCID-I; First, Spitzer, Gibbon \& Williams, 1997) before and after the treatment (the analyses demonstrated high congruency between diagnosticians: $85 \%$ congruent diagnoses; Cohen's $\kappa=0.70$ ). SCID enables one to make a diagnosis at three severity levels: mild, moderate, severe. When PTSD criteria are not met the assessment of remission is possible - full (no symptoms of a disorder), partial (too few symptoms to make a diagnosis) or past history (no symptoms for a substantial time - full recovery).

Temperamental traits were assessed by the Formal Characteristic of Behavior - Temperament Inventory (FCB-TI) developed by Strelau \& Zawadzki (1993, 1995). The inventory consists of six scales, but for this analysis, only the scores of the Emotional Reactivity and Briskness scales were taken into account. Personality disorders were assessed by the Polish version of the Personality Beliefs Questionnaire (PBQ; Beck et al., 2001), but for the purpose of this study the general factor (GFPD) reflecting maladaptive beliefs about oneself or others associated with personality pathology and leading to distress and interpersonal dysfunctions was derived from scales assessing 10 personality disorders according to DSM-IV (Jahng 


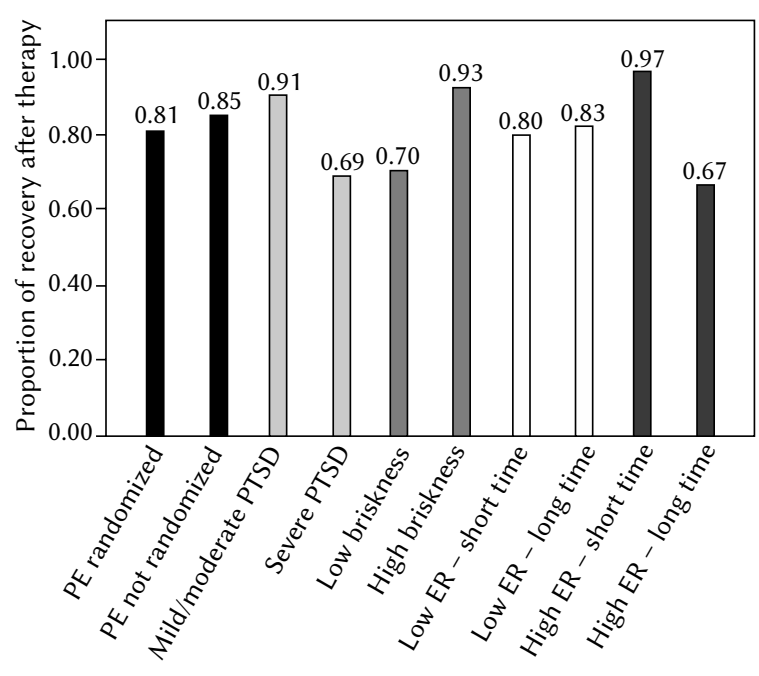

Figure 1. Proportion of remission after psychotherapy of PTSD (differences between therapy groups and subgroups distinguished on the basis of variables influencing recovery).

et al., 2011). All demographic variables (age, gender, education) as well as the time from MVA were assessed by the Inventory for MVA survivors (see: Zawadzki \& Popiel, 2012).

\section{PROCEDURE OF ANALYSIS}

Analysis was focused on pre-treatment predictors of PE effectiveness (diagnosis of PTSD after therapy). $\eta$ coefficient for continuous variables and $\varphi$ coefficient for nominal variables were calculated with diagnosis of PTSD (the sign of $\eta$ was added after the analysis of the direction of differences among groups) and logistic regression was applied. For the purpose of the study severity of pre-treatment PTSD was dichotomized into mild/moderate versus severe (in 26 subjects severity of PTSD was diagnosed as mild, in 49 as moderate, and in 48 as severe (after recoding: 75 versus 48; 39\%). Severity of PTSD and gender were introduced into logistic regression as qualitative variables, and all others as quantitative variables (BR, ER, GFPD, time after MVA and age). The prediction of education level (coded as lower vs. higher) was not significant (correlation with diagnosis of PTSD $\varphi=0.09$ ), so this variable was removed from the analysis. In the case of other variables (gender, age) they were kept in the model to control demographic differences, even if their prediction of therapy effectiveness was insignificant. The same refers to main effects of variables which served to calculate interactions (as their products). For the purpose of graphical depiction of predictions of PTSD diagnosis all continuous variables were dichotomized by appropriate medians (in the case of time after MVA: 1-11 and 12-48 months).

\section{RESULTS}

At post-treatment 22 subjects (17.9\%) still met the criteria for PTSD diagnosis, and 101 participants (81.1\%) were PTSD free (full or partial remission). The correlation analyses showed that among temperamental traits only briskness predicted effectiveness of the therapy. For other traits the $\eta$ correlations with post-treatment diagnosis were not significant (perseveration $=0.10$, sensory sensitivity $=-0.08$, activity $=0.07$ and endurance $=0.08$ ), nor were their interactions with time after MVA. In the case of emotional reactivity the main effect was not significant, but a significant effect of interaction with time after MVA

Table 1

Demographic data of subjects participating in the psychotherapy

\begin{tabular}{|c|c|c|c|c|c|c|c|}
\hline Sample & $\begin{array}{c}\text { Time after } \\
\text { MVA } \\
M(S D)\end{array}$ & $\begin{array}{c}\text { Education: } \\
\text { lower } \\
\text { vs. higher } \\
(\%)\end{array}$ & $\begin{array}{l}\text { Severity of } \\
\text { PTSD: mild } \\
\text { vs. severe } \\
(\%)\end{array}$ & $N$ & Gender & $\begin{array}{c}\text { Age } \\
\text { (range) }\end{array}$ & $\begin{array}{c}\text { Age } \\
M(S D)\end{array}$ \\
\hline randomized $\mathrm{PE}$ & $\begin{array}{c}14.98 \\
(17.83)\end{array}$ & $7 / 82(92.1)$ & $50 / 39(43.8)$ & 89 & $69 \mathrm{~F} / 20 \mathrm{M}$ & $18-82$ & $\begin{array}{c}39.54 \\
(13.77)\end{array}$ \\
\hline $\begin{array}{c}\text { not randomized } \\
\text { PE }\end{array}$ & $\begin{array}{c}22.09 \\
(25.20)\end{array}$ & 3/31 (91.2) & $25 / 9(26.5)$ & 34 & $29 \mathrm{~F} / 5 \mathrm{M}$ & $18-59$ & $\begin{array}{c}33.99 \\
(10.40)\end{array}$ \\
\hline total & $\begin{array}{c}16.94 \\
(20.28)\end{array}$ & 10/113 (91.9) & 75/48 (39.0) & 123 & $98 \mathrm{~F} / 25 \mathrm{M}$ & $18-82$ & $\begin{array}{c}38.00 \\
(13.13)\end{array}$ \\
\hline
\end{tabular}

Note. Differences between groups for $d f=1$ : gender $\chi^{2}=0.92, p=0.34$, education $\chi^{2}=0.03, p=0.86$, severity of pre-treatment PTSD $\chi^{2}=3.11, p=0.08$, post-treatment diagnosis of PTSD $\chi^{2}=0.32, p=0.57$; age $t=2.41, d f=79$ (unequal variances), $p=0.02$, time after MVA $t=1.51, d f=46$ (unequal variances), $p=0.08$, briskness $t=0.61, d f=121, p=0.54$, emotional reactivity $t=1.03$, $p=0.31$ and GFPD $t=0.25, p=0.80$. 
Table 2

Coefficients of correlations between demographic variables, pre-treatment PTSD severity, temperamental traits assessed before therapy and post-therapy diagnosis of PTSD and results of logistic regression for predictors of post-therapy diagnosis of PTSD

\begin{tabular}{|c|c|c|c|}
\hline $\begin{array}{c}\text { Diagnosis of PTSD } \\
(1=\text { recovery } / 0=\text { PTSD })\end{array}$ & $\begin{array}{l}\text { Correlations } \\
\qquad\left(\eta \& \varphi^{\#}\right)\end{array}$ & $\begin{array}{l}\text { Logistic } \\
\text { regression }-B\end{array}$ & $\begin{array}{l}\text { Logistic } \\
\text { regression }-e^{B}\end{array}$ \\
\hline Gender $(F=1 / M=2)^{@}$ & $0.08^{\#}$ & 0.04 & 1.05 \\
\hline Age & $-0.19^{*}$ & -0.02 & 0.98 \\
\hline $\begin{array}{c}\text { Time from MVA to the beginning } \\
\text { of the therapy (time) }\end{array}$ & $-0.23^{*}$ & -0.26 & 0.77 \\
\hline $\begin{array}{l}\text { Severity of pre-treatment PTSD } \\
\text { (mild/moderate versus severe) }^{@}\end{array}$ & $-0.28^{* \#}$ & $1.30^{*}$ & 3.67 \\
\hline Briskness (BR) & $0.31^{*}$ & $1.06^{*}$ & $2.88^{*}$ \\
\hline Emotional reactivity (ER) & -0.03 & 0.72 & 2.06 \\
\hline Interaction (Time $\times$ ER) & $-0.27^{*}$ & $-0.97^{*}$ & 0.38 \\
\hline Constant term & $x$ & $2.23^{*}$ & 9.27 \\
\hline Personality disorders (GFPD) & $-0.18^{*}$ & -0.55 & 0.58 \\
\hline
\end{tabular}

Note. ${ }^{\circledR}$ - qualitative variable in logistic regression.

Coefficients of correlations (or effects in logistic regression) significant at $p<0.05$ are marked by an asterisk.

was found. For other variables significant prediction of therapy effectiveness was found for age (lower effectiveness in subjects of older age), personality pathology (lower effectiveness in subjects with higher GFPD score - more symptoms of personality disorders), severity of PTSD (lower effectiveness for subjects suffering from more severe PTSD prior to the therapy), and time from MVA (lower effectiveness in longer time since MVA; see Table 2).

In logistic regression the only significant prediction was found for severity of PTSD, briskness and interaction between emotional reactivity and time after MVA (the statistics for the whole model with eight predictors: $\chi^{2}=32.47, d f=8, p=0.000 ; R^{2}$ Nagelkerke $=0.41 ; 84.8 \%$ of correct overall classifications). The effect obtained for personality disorders was not significant, due to the remarkable correlations with other predictors: BR (Pearson's $\left.r=-0.36^{*}\right)$, ER $\left(r=0.36^{*}\right)$, severity of pre-treatment PTSD $\left(\eta=0.24^{*}\right)$, and time after MVA $\left(r=0.16^{*}\right)$. The odds ratio was the highest for severity of PTSD, indicating that subjects with less severe PTSD had about 4 times higher chance for remission than subjects with severe PTSD. Subjects with higher briskness had about 3 times higher chance for recovery than subjects with low briskness and a very similar result was found for interaction between emotional reactivity and time after MVA. The ratios of remission for all these variables are depicted in bars in Figure 1. Significant differences in therapy effectiveness for dichotomized time were found only for more highly emotionally reactive subjects $\left(\chi^{2}=12.95, d f=1, p=0.000\right.$; for lower ER subjects: $\left.\chi^{2}=0.35, d f=1, p=0.55\right)$.

\section{DISCUSSION}

The findings of the study showed that the pre-treatment severity of PTSD symptoms was the main factor predicting remission under therapy (H3 confirmed). This result is in line with data from other studies and suggests that the standard treatment protocol is not equally effective in treating the full range of severity of PTSD. Probably some modifications are needed, for example increasing the number of sessions, continuing therapy or applying other forms of treatment (such as cognitive therapy procedures) or even combining psychotherapy and pharmacotherapy. The results also confirmed expectations that high briskness predicts the recovery from PTSD (H1). Earlier studies showed that briskness is related to the "avoidance" cluster of symptoms of PTSD and to decrease of symptoms of PTSD during natural recovery, which is in line with the results obtained for psychotherapy (Strelau \& Zawadzki, 2004; Zawadzki \& Popiel, 2012). This trait reflecting individual behavioral plasticity may be considered as a factor promoting change of symptoms in psychotherapy. It would also be in line with a central role attributed by Foa et al. (2007) to avoidance in maintaining PTSD. 
Patients scoring higher on briskness might benefit from both main methods in the Prolonged exposure protocol - in vivo and imaginal exposure. In vivo-exposure requires change of avoidant behavior towards confronting anxiety provoking stimuli, to promote extinction learning. Prolonged imaginal exposure enables confrontation with trauma memory with the aim to process it - and to turn "traumatic memories" into "narrative memories" (Brewin, 2005). Processing of traumatic memories means generating new explanations. Some support for the role of briskness in this process may be drawn from the area of creativity Nęcka and Hławacz (2013) found that high briskness and low emotional reactivity predict divergent thinking... in artists. Recent longitudinal studies showed, however, that the level of briskness decreases under long-lasting symptoms of PTSD (Zawadzki \& Popiel, 2012), which is also suggested by the data obtained in this study ( $\eta$ correlations with time after MVA $-0.38^{*}$ for BR and $0.21^{*}$ for ER). The interaction of briskness with time after MVA was not significant in predicting recovery from PTSD, which suggests that - even though briskness has already been changed by symptoms of the disorder in the longer term - its beneficial effect through time remains. The differences in the initial level of temperamental traits among groups entering therapy in different periods may be due to the interaction between temperament and the time that passed since the accident when treatment was initiated, but it is also in line with expected changes of BR under symptoms of PTSD. Further studies on factors which influence differences in the decision of entering therapy are necessary.

The most controversial result refers to the effect of time on recovery from PTSD especially in relation to emotional reactivity. Although the main effect of ER was not significant, the findings suggest an important role of time for highly emotionally reactive subjects. Based on the results of previous studies (Strelau \& Zawadzki, 2011; Zawadzki \& Popiel, 2012) it was expected that high emotional reactivity would be a risk factor for PTSD (which in part was confirmed by significant $\eta$ correlation for emotional reactivity $0.24^{*}$ and severity of pre-treatment PTSD), but at a time it predicts easiness of recovery from PTSD (e.g. decrease of symptoms during process of natural recovery). The findings disconfirmed this expectation (H2), showing that time affects recovery from PTSD only in highly emotionally reactive subjects (the rate of recovery is much lower with longer time passing from MVA). This result needs additional empirical confirmation as well as the finding showing that effectiveness of therapy in a shorter time is higher for high ER subjects than low ER persons, which is absolutely not in line with theoretical expectations (see Strelau \& Zawadzki, 2011). Our speculative interpretation considers the effect of interaction of ER and time after traumatic event for recovery from PTSD as a form of interplay between the subjects' motivation to treat and the opportunity of successful recovery (determined among others by personality disorders). Assuming that high ER subjects are more highly motivated in general than low ER persons, it may be expected that in a short time after MVA their high motivation to treat enables one to overcome the barriers of recovery, but in a longer perspective precisely the opposite tendency may be expected, when the limitations are more severe and the motivation is not sufficient for successful recovery. Low ER subjects are less motivated to treat, but they are less prone to develop the symptoms of personality disorders without regard for time passing from MVA (in effect their recovery rate remains stable in different periods). Only a part of this explanation may be demonstrated on the basis of results of this study, specifically concerning the data obtained for personality disorders, which predict recovery (confirmed H4), and highly correlate with other predictors. The linear regression of GFPD (controlled for age and gender) showed significant effects of ER (semi-partial correlation: 0.33), severity of pre-treatment PTSD (0.18) and interaction of time and ER (0.17) - the model with six independent variables (without a non-significant effect of $\mathrm{BR})$ explained $22 \%$ of variance $(R=0.46)$. The model limited to the time after MVA (0.07), ER $\left(0.37^{*}\right)$ and their interaction $\left(0.19^{*}\right)$ explained $17 \%$ of variance of GFPD $(R=0.41)$. The interaction showed that low ER demonstrated a low level of personality pathology regardless of the time, but the level of GFPD increased rapidly in high ER persons in a longer time in comparison to shorter period after MVA as well as in comparison to low ER persons (the correlation of GFPD with ER was equal $0.21^{*}$ and $0.50^{*}$ respectively in both periods of time). In this line of interpretation the long-lasting symptoms of PTSD increase the level of personality pathology, reflected in maladaptive (rigid) beliefs about oneself or others and associated with distress and interpersonal dysfunctions (Livesley \& Jang, 2000) and may be considered as a factor which limits recovery from PTSD. It may explain the higher rate of recovery in a shorter time as well as lower rate for ER subjects in a longer time. Further studies on subjects' motivation to undergo treatment are needed to verify this interpretation, especially with relationship to individual factors. It suggests, however, the important role of temperament dimensions as factors predicting psychotherapy effectiveness. It can also be concluded that high ER subjects should enter therapy relatively early, due to the expected high chance of recovery and relatively high risk of developing personality disorders (associated with changes in temperament itself) and high risk of unsuccessful therapy in a longer time perspective. In the case of low ER subjects the time passing from traumatic event is less important, due to their higher chance for natural recovery. It is, however, also limit- 
ed by the risk of a possible process of "complication", leading to development of personality disorders and changes in temperament under long-lasting symptoms of PTSD. It means that if PTSD symptoms do not spontaneously decrease with time, also low ER individuals should not postpone treatment.

The paper was supported by Grant PL0088 "Psychological causes and consequences of traffic accidents" from the Financial Mechanism Committee established by Iceland, Liechtenstein and Norway through the EEA Mechanism and the Polish Minister of Science and Higher Education.

\section{References}

Beck, A.T., Butler, A.C., Brown, G.K., Dahslgaard, K.K., Newman, C.F. \& Beck, J.S. (2001). Dysfunctional beliefs discriminate personality disorders. Behavioral Research and Therapy, 39, 1213-1225.

Brewin, C. (2005). Implications for psychological intervention. In: J. Vasterling \& C. Brewin (eds.). Neuropsychology of PTSD: biological, cognitive and clinical perspectives (pp. 271-290). New York: Guilford Press.

Cloninger, C.R., Svrakic, D.M. \& Przybeck, T.R. (1993). A psychobiological model of temperament and character. Archives of General Psychiatry, 50, 975990.

First, M.B., Spitzer, R.L., Gibbon, M. \& Williams, J.B.W. (1997). Structured Clinical Interview for DSM-IV Axis I disorders. Washington, DC: American Psychiatric Press.

Foa, E.B., Hembree, E.A. \& Rothbaum, B.O. (2007). Prolonged exposure therapy for PTSD. Oxford: Oxford University Press.

Hembree, E.A., Cahill, S.P. \& Foa, E.B. (2004). Impact of personality disorders on treatment outcome for female assault survivors with chronic posttraumatic stress disorder. Journal of Personality Disorders, 18, 117-127.

Hornowska, E. (2003). Temperamentalne uwarunowania zachowania. Badania z wykorzystaniem kwestionariusza TCI R.C. Cloningera [Temperamental influences on behaviour. Studies with TCl R.C. Cloninger's inventory]. Poznań: Bogucki Wydawnictwo Naukowe.

Jacobson, N. \& Truax, P. (1991). Clinical significance: A statistical approach to defining meaningful change in psychotherapy research. Journal of Consulting and Clinical Psychology, 59, 12-19.

Jahng, S., Trull, T.J., Wood, P.K., Tragesser, S.L., Tomko, R., Grant J.D., Bucholz, K.K. \& Sher, K.J. (2011). Distinguishing general and specific personality disorder features and implications for substance dependence comorbidity. Journal of Abnormal Psychology, 120, 656-669.
Joyce, P., McKenzie, J., Carter, J., Rae, A., Luty, S., Frampton, C. \& Mulder, R. (2007). Temperament, character and personality as predictors of response to interpersonal psychotherapy and cognitive-behavioural therapy for depression. The British Journal Of Psychiatry: The Journal Of Mental Science, 190, 503-508.

Lehner, M., Wisłowska-Stanek, A. \& Płaźnik, A. (2009). Wygaszanie reakcji emocjonalnej jako nowy cel farmakoterapii zaburzeń lękowych. Psychiatria Polska, 18, 639-654.

Livesley, W.J. \& Jang, K.L. (2000). Toward an empirically based classification of personality disorder. Journal of Personality Disorders, 14, 137-151.

Lommen, M., Engelhard, I., Sijbrandij, M., van den Hout, M. \& Hermans, D. (2013). Pre-trauma individual differences in extinction learning predict posttraumatic stress. Behaviour Research and Therapy, 51, 63-67. doi:10.1016/j.brat.2012.11.004.

Nęcka, E. \& Hławacz, T. (2013). Who has an artistic temperament? Relationships between creativity and temperament among artists and bank officers. Creativity Research Journal, 25, 182-188. doi: 10.1080/10400419.2013.783744.

National Institute for Health and Clinical Excellence, NICE (2005). NICE Treatment Guideline: PTSD (2005). London: Author.

Popiel, A. \& Pragłowska, E. (2008). Psychoterapia poznawczo-behawioralna. Teoria i praktyka [Cognitive-behavioural psychotherapy. Theory and practice]. Warszawa: Paradygmat.

Popiel, A., Zawadzki, B., Pragłowska, E. \& Teichman, Y. (in preparation to press). A randomized controlled trial of prolonged exposure, paroxetine and combined treatment for PTSD following motor vehicle accident - the "TRAKT" study.

Strelau, J. (1998). Temperament: A psychological perspective. New York: Plenum Press.

Strelau, J. \& Zawadzki, B. (1993). The Formal Characteristics of Behaviour - Temperament Inventory (FCB-TI): Theoretical assumptions and scale construction. European Journal of Personality, 7, 313-336.

Strelau, J. \& Zawadzki, B. (1995). The Formal Characteristics of Behavior - Temperament Inventory (FCB-TI): Validity studies. European Journal of Personality, 9, 207-229.

Strelau, J. \& Zawadzki, B. (2004). Trauma and temperament as predictors of posttraumatic stress disorder and its dimensions 3, 15 months and two years after experiencing flood. Polish Psychological Bulletin, 35, 5-13.

Strelau, J. \& Zawadzki, B. (2011). Fearfulness and anxiety in research on temperament: Temperamental traits are related to anxiety disorders. Personality and Individual Differences, 50, 907-915.

Tarrier, N., Sommerfield, C., Pilgrim, H. \& Faragher, B. (2000). Factors associated with outcome of cognitive-behavioural treatment of chronic post-trau- 
matic stress disorder. Behaviour Research and Therapy, 38, 191-202.

Van Minnen, A., Arntz, A. \& Keijsers, G.P.J. (2002). Prolonged exposure in patients with chronic PTSD: predictors of treatment outcome and dropout. Behaviour Research and Therapy, 40, 439-457.

Weertman, A., Arntz, A., Schouten, E. \& Dreessen, L. (2005). Influences of beliefs and personality disorders on treatment outcome in anxiety patients. Journal of Consulting and Clinical Psychology, 73, 936-944.

Wessa, M. \& Flor, H. (2007). Failure of extinction of fear responses in Posttraumatic Stress Disorder: Evidence from second-order conditioning. American Journal of Psychiatry, 164, 1684-1692.

Zawadzki, B. \& Popiel, A. (2012). Temperamental traits and severity of PTSD symptoms: The data from longitudinal studies of motor vehicle accidents survivors. Journal of Individual Differences, 33, 257-267. 